\title{
The Influence of Social Media Affinity on Eating Attitudes and Body Dissatisfaction in Philippine Adolescents
}

\author{
Shannen Tadena ${ }^{1}$, So Ra Kang ${ }^{2}$, Shin-Jeong $\mathrm{Kim}^{3}$ \\ ${ }^{1}$ Master Student, School of Nursing, Hallym University, Chuncheon; ${ }^{2}$ Visiting Professor, Division of Nursing, Ewha Womans University, Seoul; ${ }^{3}$ Professor, School \\ of Nursing · Research Institute of Nursing Science, Hallym University, Chuncheon, Korea
}

Purpose: This study aimed to examine the influence of social media affinity on eating attitudes and body dissatisfaction among adolescents in the Philippines. Methods: The participants were 114 junior high school students enrolled in 7th to 10th grade in Cavite Province, Philippines. The collected data were analyzed in SPSS, using descriptive statistics, the independent t-test, one-way analysis of variance, Pearson correlation coefficients, and stepwise multiple linear regression. Results: The factors affecting eating attitudes were body dissatisfaction ( $\beta=-.47, p<.001)$, social media affinity ( $\beta=.33, p<.001)$ and grade (10th grade) $(\beta=-.28, p<.001)$, and the factors influencing body dissatisfaction were eating attitudes $(\beta=-.65, p<.001)$ and social media affinity $(\beta=.17, p=.041)$. Conclusion: In order to promote healthy eating attitudes and to improve body satisfaction among Philippine adolescents, educational strategies tailored to social media users will be needed.

Key words: Adolescent; Body dissatisfaction; Eating; Attitude; Social media

\section{Corresponding author Shin-Jeong Kim}

https://orcid.org/0000-0003-2582-3436

School of Nursing · Research Institute of Nursing Science, Hallym University, 1 Hallymdaehak-gil, Chuncheon 24252, Korea

TEL +82-33-248-2721 FAX +82-33-248-2734

E-MAIL ksj@hallym.ac.kr

*This study was supported by the research fund of Hallym University in 2019 (HRF 202001-008)

Received Jan 1, 2020 Revised Jan 8, 2020 Accepted Jan 9, 2020
(-) This is an Open Access article distributed under the terms of the Creative Commons Attribution NonCommercial License (http://creativecommons.org/licenses/by-nc/4.0/) which permits unrestricted noncommercial use, distribution, and reproduction in any medium, provided the original work is properly cited.

\section{INTRODUCTION}

The use of the internet for social networking has become a global phenomenon, as the number of social network users worldwide increased from 2.3 billion in 2016 to around 2.6 billion in 2018 [1]. This means that nearly half (45\%) of the earth's entire population uses a social networking service (SNS) [2]. Usage is especially high among adolescents, with $92 \%$ of United States (US) adolescents reporting daily social media (SM) use, and $24 \%$ of those teens stating that they go online "almost constantly" [3]. In the Philippines, 50\% of Filipinos aged 14 to 23 reported using the internet to expand their relationships by joining SNS [4].

SM refers to web-based and mobile technologies, usually free, that employ online tools to enable social interactions through dialogue [5]. Well-known SM include Facebook, WhatsApp, Twitter, and Instagram. These SM gain users attracted by their "social" characteristics, such as text-audio visual appeal, openness, and connectedness [6]. A vast amount of information is exchanged among users who may be friends or family, but are just as likely to be total strangers across the globe. In this way, SM has the power to affect individuals' lives significantly by shaping their thoughts, values, and attitudes [7].

A study conducted in 2015 by a Korean government research institute reported that SM had both advantages (e.g., social connectivity, social involvement, information attain- 
ment, and entertainment) and disadvantages (e.g., social risk, time consumption, psychological risks, and privacy concerns) [8]. Another study [6] stated that the use of SM by adolescents increased connectedness and intimacy with their peers. While some studies have found empirical evidence to support an association between SM use and positive mental health outcomes, such as improved social self-concept and self-esteem [9], others have found associations between SM use and health problems, such as anxiety, sleep problems, and low self-esteem [10].

Adolescence marks a period of rapid developmental changephysical, emotional, psychological, and social. Many adolescents begin learning and making decisions about healthy behaviors for the first time. For adolescents, one factor that can change is their eating habits, which are subject to many influences, such as environmental cues from advertising and media, including SM. Studies have shown a significant relationship between the use of SM and problematic eating habits [6]. Therefore, it is essential to engage in healthy lifestyle practices, such as consuming a nutritionally balanced diet [11].

Peer groups play a major role in establishing adolescents' social norms, such as their views and values about body appearance [12]. Through dialogues with peers using SM, they assimilate social norms and attitudes, and it has been shown that peer groups can affect adolescents' body satisfaction [13]. In the Philippines, a study among high school students concluded that every time the respondents received a like for their pictures posted on SNS, they felt a boost to their body image [14]. Another study found that the more frequently adolescents engaged in SM activities, the more negative talk they encountered about how they and others compared to the so-called "perfect" body images posted on SM [15].

Festinger's social comparison theory helps to explain this phenomenon in adolescents [15]. According to this theory [15], people make self-evaluations by comparing themselves with others. When people compare themselves to others whom they consider superior in some way (e.g., thinner, more attractive, more popular), they can come to view themselves negatively. Although adolescents may recognize that the models they see in the media are not realistic role models, peer pressure can lead them to compare themselves to the images posted on SM, leading to negative satisfaction with their own bodies. The more they idealize thinness or other attributes, the more dissatisfied they become with how they measure up to what is considered body perfection on SM.

In the Philippines, adolescents aged 13 18 ranked first in internet usage time, averaging 9 hours and 29 minutes daily, with SM usage time averaging 4 hours and 12 minutes [2]. According to a survey conducted by Kantar Media [16], SM greatly influences where and what Filipinos eat. Surprisingly, it also showed that $80 \%$ of Filipino adolescents aged $10 \sim 19$ were users of SM.

In addition, Philippine adolescents are exposed to unhealthy food and beverages, including in their schools and the surrounding areas [17]. During an analysis of changes over a recent 17-year time period in the Philippines, the obesity rate has risen dramatically, and adolescents are no exception to this trend [18]. This tendency causes adolescents who are sensitive about their appearance to be dissatisfied with their body image. Many studies have found evidence supporting a relationship between body dissatisfaction and unhealthy eating disorders [19].

Because of its subliminal influences, inappropriate use or overuse of SM can pose risks, especially for adolescents, given their high usage rates. It is important that adolescents understand the unintended consequences of SM [10]. The influences of SM on health have not been extensively studied, and little empirical evidence has been gathered on SM's impact on adolescents' eating attitudes, body dissatisfaction, and the pursuit of thinness rather than fitness [20]. This is a particularly critical issue for adolescents aged 1318 in the Philippines due to their high internet usage time and concomitant exposure to various effects of SM usage.

\section{Purpose}

The purpose of this study was to examine the influence of social media affinity on eating attitudes and body dissatisfaction among adolescents in the Philippines. The specific purposes were to identify (1) participants' degree of social media affinity, eating attitudes, and body dissatisfaction; (2) the differences in social media affinity, eating attitudes, and body dissatisfaction according to participants' characteristics; (3) the relationships between social media affinity, eating attitudes, and body dissatisfaction; and (4) the influence of social media affinity on eating attitudes and body dissatisfaction.

\section{METHODS}

\section{Design}

This descriptive study was conducted to identify the degree of social media affinity, eating attitudes, and body dissatisfaction of Filipino adolescents and to examine the effects of social media affinity on their eating attitudes and body dissatisfaction.

\section{Research Participants and Procedures}

The participants comprised adolescents who were students 
in grades 7 through 10 enrolled at a private coeducational high school in Cavite Province, Philippines. The participants were aged 12 to 17 years and used SM. The school was selected using convenience sampling. Researchers recruited participants by assigning students a number corresponding to their class and choosing numbers through random selection to give everyone the same chance of representing their year level.

The final sample size was 114 students. Using the $G^{*}$ Power 3.1 program, it was determined that 103 participants were required to achieve an effect size of .15, a significance level of .05 , and a test power of .80 in a multiple regression analysis with seven independent variables.

\section{Measurements}

\section{1) Social media affinity}

Social media affinity is defined as a person's fondness for or frequent usage of SM [21]. We used the scale developed and validated by Gerlich et al. [21], although some questions (such as item 7 and 12) were modified to fit the target population of this study. Authorization to use the scale was provided by the author. This scale is a 13-item instrument developed to measure respondents' beliefs about SM using a 5-point Likert scale (1=strongly disagree, $2=$ disagree, $3=$ neutral, $4=$ agree, and $5=$ strongly agree) to rate the items, of which nine are stated in the positive and four in the negative. Higher scores indicate a higher social media affinity. The Cronbach's $\alpha$ was calculated to be .77 by Gerlich et al. [21], and a Cronbach's $\alpha$ value of .73 was found for the internal reliability of this study.

\section{2) Eating attitude}

We used the Eating Attitudes Test (EAT 26) scale developed by Garner, Olmsted, Bohr, and Garfinkel [22], which is composed of 26 items measuring three factors: dieting, bulimia and food preoccupation, and oral control. Permission to use the scale was acquired through the EAT 26 website. The items are scored using a 4 -point Likert scale $(0=$ never, nearly, sometimes, $1=$ often, $2=$ usually, $3=$ always), with one reversecoded item (item 26). A cutoff score of 20 or above out of a total of 78 indicates a high risk of developing an eating disorder. Garner et al. [22] reported that the Cronbach's $\alpha$ of this tool was .85 for adolescents and .86 for adults. In this study, it was .89 .

\section{3) Body dissatisfaction}

We used the Body Shape Questionnaire (BSQ), a self-report scale that assesses body dissatisfaction and eating disorder pathology in a clinical setting. For this study, we used a shorter form, the BSQ 8-c, developed by Evans and Dolan [23]. The author allowed the use of the scale. Each item was scored from
1 to $6(1=$ never, $2=$ rarely, $3=$ sometimes, $4=$ often, $5=$ very often, and $6=$ always). Scores less than 19 mean no concerns with shape, scores of 19 25 indicate mild concern, scores of 26 33 mean moderate concern, and scores over 33 indicate marked concern. The Cronbach's $\alpha$ of this tool was reported to be .93 [23], and it was also high (.92) in this study.

\section{Data Collection}

After receiving approval from the Institutional Review Board (IRB), we coordinated with the administration staff of a coeducational private school. We sent an e-mail addressed to the rector and the head of the school describing the timetable for gathering data, the research tools, and the purpose of the study. After receiving approval to conduct data collection, we randomly picked four numbers for each grade, with each number representing a class from each grade. Endorsement letters and both student and parent consent forms were distributed to the students and their parents to be signed as proof that they were willing to participate in the study. After a week, the consent forms were returned and we distributed the questionnaires to each class during their break time with the permission of participants, who indicated that completing the survey would not disturb the class. Researchers gave instructions regarding the questionnaires and remained in the classroom during the entire duration of data collection to respond to any questions or needs for clarification. The respondents were asked to tick the box or number that represented their answer. Some respondents approached the researchers for clarifications. One example of a clarification was for item 26 (I enjoy trying new rich foods) from the EAT 26 tool. The researchers explained this as item as referring to foods with a high caloric content. Answering the questionnaires took around 15 minutes for each participant. After data collection, the participants were compensated with a snack for the time they spent answering the questionnaires. The collected questionnaires were kept and locked in the cabinet of the corresponding author's research room and were not accessible to any other researchers.

\section{Ethical Considerations}

Ethical approval of this study was granted by the Institutional Review Board (No: HIRB 2018-067) of Hallym University, with which the first researcher is affiliated; voluntary participation, anonymity, and confidentiality were ensured throughout the study. The IRB confirmed that no element of this study would violate human rights and that all materials and processes conformed to proper ethical research procedures. 


\section{Data Analysis}

Data were analyzed with SPSS version 22.0 software (IBM Corp., Armonk, NY, USA). The frequency, percentage, mean, and standard deviation were used to describe participants' general characteristics and variables. The t-test and analysis of variance were used to analyze differences in social media affinity, eating attitudes, and body dissatisfaction. The Scheffé test was conducted as a post-comparison test. Correlations between social media affinity, eating attitudes, and body dissatisfaction were assessed by Pearson correlation. Stepwise multiple regression was used to ascertain the influence of social media affinity on eating attitudes and body dissatisfaction.

\section{RESULTS}

\section{Descriptive Characteristics: Degree of Social Media Affi- nity, Eating Attitudes, and Body Dissatisfaction}

The descriptive characteristics of the sample are shown in Table 1. Out of the 114 participants, $51.8 \%(n=59)$ were male and $48.2 \%(n=55)$ were female, and their ages were 1217 years old, with mean of $14.1 \pm 1.43$ years. Thirty-three of the participants $(28.9 \%)$ were in 10th grade, followed by $32(28.1 \%)$ in seventh and eighth grade and $17(14.9 \%)$ in ninth grade. The most commonly used SNS was Facebook Messenger $(n=107$, 93.9\%). Among the 114 participants, the majority used SNS every day $(n=91,79.8 \%)$. Cell phones were the predominant device used to check SM $(n=110,96.5 \%)$. The most common purpose of using social media was communication $(n=107$, $93.9 \%$ ). The mean score for social media affinity was 45.54 \pm 6.49 out of 65.0 , which indicated a relative affinity for SM. The score for eating attitudes was $37.43 \pm 14.74$ out of 78.0 , and a score of less than 20 was found in $10.5 \%(n=12)$ of the participants, while a score above 20 indicating a high risk of developing eating disorders-was found in $89.5 \%(n=102)$ of the participants. In addition, the average body dissatisfaction score was $22.72 \pm 9.81$ out of 48.0 , indicating mild concern about body shape. No concern with body shape was found in $38.6 \%(n=44)$ of the participants, mild concern in $27.2 \%(n=31)$, moderate concern in $21.0 \%(n=24)$, and marked concern in $13.2 \%(n=15)$.

\section{Social Media Affinity, Eating Attitudes, and Body Dissatis- faction According to Participants' General Character- istics}

Patterns in social media affinity, eating attitudes, and body dissatisfaction according to participants' general characteristics are shown in Table 2 . Social media affinity was signifi- cantly higher among female participants than among male participants $(\mathrm{t}=2.22, p=.036)$ and in participants who reported everyday SM use than among those who reported a weekly use of 6 days or fewer $(t=2.68, p=.006)$. The scores for eating attitudes in the 12 13 and 14 15 age groups were significantly higher than those in the $16 \sim 17$ age group $(\mathrm{F}=10.46$, $p<.001)$. The scores for eating attitudes of participants in grades 7,8 , and 9 were significantly higher than those of participants in grade $10(\mathrm{~F}=9.37, p<.001)$. Body dissatisfaction was significantly higher in the 16 17 age group than in the 12 13 age group $(\mathrm{F}=3.30, p=.041)$. In addition, body dissatisfaction was highest among the participants in grade 10, but the Scheffé test showed no significance $(\mathrm{F}=4.35, p=.006)$.

\section{Correlations between Social Media Affinity, Eating Atti- tudes, and Body Dissatisfaction}

Participants' social media affinity was significantly correlated with their eating attitudes $(\mathrm{r}=-.37, p<.001)$. In addition, their eating attitudes were significantly correlated with body dissatisfaction $(\mathrm{r}=-.59, p<.001)$ (Table 3).

\section{Factors Influencing Eating Attitudes and Body Dissatis- faction}

Multicollinearity and the variance inflation factor (VIF) were checked to determine whether the assumptions of multiple regression analysis were satisfied. The correlation coefficients among the independent variables ranged from .60 to .41 and the Durbin-Watson statistics were 1.65 and 0.70 , indicating no multicollinearity. No variables had an explanatory power over .80, and the VIF was under 10, which did not exceed the standard. Therefore, multicollinearity was not present. Multiple regression analysis of eating attitudes was conducted using age, grade (dummy variable), body dissatisfaction, and social media affinity. In addition, multiple regression analysis of body dissatisfaction was performed using age, grade (dummy variable), eating attitudes, and social media affinity (Table 4$)$. The factors found to influence eating attitudes were body dissatisfaction $(\beta=.47, p<.001)$, social media affinity $(\beta=.33, p<.001)$, and grade (10th grade) $(\beta=.28, p<$ .001 ), which explained $52.4 \%$ of the variance in eating attitudes $(\mathrm{F}=40.28, p<.001)$. The factors found to influence body dissatisfaction were eating attitudes $(\beta=.65, p<.001)$ and social media affinity $(\beta=.17, p=.041)$ which explained the $36.8 \%$ of the variance in body dissatisfaction $(\mathrm{F}=32.28, p<.001)$.

\section{DISCUSSION}

In modern society, it is virtually impossible to ignore the in- 
Table 1. Characteristics and Social Media Affinity, Eating Attitudes, and Body Dissatisfaction of Participants

\begin{tabular}{|c|c|c|c|}
\hline Demographic characteristics & Categories & $\mathrm{n}(\%)$ & $\mathrm{M} \pm \mathrm{SD}$ \\
\hline Gender & $\begin{array}{l}\text { Male } \\
\text { Female }\end{array}$ & $\begin{array}{l}59(51.8) \\
55(48.2)\end{array}$ & \\
\hline Age (year) & $\begin{array}{l}12 \sim 13 \\
14 \sim 15 \\
16 \sim 17\end{array}$ & $\begin{array}{l}42(36.8) \\
45(39.5) \\
27(23.7)\end{array}$ & $14.1 \pm 1.4$ \\
\hline Grade & $\begin{array}{l}\text { 7th } \\
8 \text { th } \\
9 \text { th } \\
10 \text { th }\end{array}$ & $\begin{array}{l}32(28.1) \\
32(28.1) \\
17(14.9) \\
33(28.9)\end{array}$ & \\
\hline Preferred SNS* & $\begin{array}{l}\text { Facebook } \\
\text { Facebook Messenger } \\
\text { Twitter } \\
\text { Instagram } \\
\text { Tumblr } \\
\text { Skype } \\
\text { Snapchat } \\
\text { Viber/Kakao Talk } \\
\text { Others }\end{array}$ & $\begin{array}{c}106(93.0) \\
107(93.9) \\
62(54.4) \\
70(61.4) \\
9(7.9) \\
6(5.3) \\
38(33.3) \\
9(7.9) \\
9(7.9)\end{array}$ & \\
\hline Weekly use (day) & $\begin{array}{l}1 \times \\
2 \times \\
3 \times \\
4 \times \\
5 \times \\
6 \times \\
\text { Every day }\end{array}$ & $\begin{array}{c}3(2.6) \\
3(2.6) \\
7(6.2) \\
5(4.4) \\
4(3.5) \\
1(0.9) \\
91(79.8)\end{array}$ & \\
\hline $\begin{array}{l}\text { Device used to check } \\
\text { social media* }\end{array}$ & $\begin{array}{l}\text { Cell phone } \\
\text { Computer } \\
\text { Tablet/iPad }\end{array}$ & $\begin{array}{r}110(96.5) \\
52(45.6) \\
26(22.8)\end{array}$ & \\
\hline $\begin{array}{l}\text { Purpose of using } \\
\text { social media* }\end{array}$ & $\begin{array}{l}\text { Communication } \\
\text { Watching video } \\
\text { Posting pictures } \\
\text { Updating self with latest news } \\
\text { Reading articles } \\
\text { Educational purposes } \\
\text { Other }\end{array}$ & $\begin{array}{r}107(93.9) \\
89(78.1) \\
60(52.6) \\
65(57.0) \\
42(36.8) \\
86(75.4) \\
4(3.5)\end{array}$ & \\
\hline Social media affinity & Total & & $45.54 \pm 6.49$ \\
\hline Eating attitudes & $\begin{array}{l}\text { Less than } 20 \\
\text { Above } 20 \\
\text { Total }\end{array}$ & $\begin{array}{r}12(10.5) \\
102(89.5)\end{array}$ & $\begin{array}{l}10.58 \pm 6.90 \\
40.59 \pm 11.92 \\
37.43 \pm 14.74\end{array}$ \\
\hline Body dissatisfaction & $\begin{array}{l}\text { No concern with shape } \\
\text { Mild concern }^{\dagger} \\
\text { Moderate concern }^{\S} \\
\text { Marked concern } \\
\text { Total }\end{array}$ & $\begin{array}{l}44(38.6) \\
31(27.2) \\
24(21.0) \\
15(13.2)\end{array}$ & $\begin{array}{l}13.11 \pm 3.02 \\
22.39 \pm 1.84 \\
29.46 \pm 2.11 \\
40.80 \pm 3.91 \\
22.72 \pm 9.81\end{array}$ \\
\hline
\end{tabular}

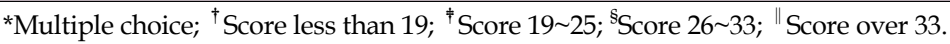

fluence of SM, which is a rapid communication method and a useful source of various types of information in everyone's daily lives [21]. The impact of SM is especially significant on teenagers, who have grown up with this technology, media use, and reliance on electronic communication $[7,12]$. Therefore, it is important to understand the impacts of social media affinity on adolescents' health.

This study found that the degree of social media affinity 
Table 2. Differences in Participants' Social Media Affinity, Eating Attitudes, and Body Dissatisfaction According to Their Characteristics

$(N=114)$

\begin{tabular}{|c|c|c|c|c|c|c|c|}
\hline \multirow{2}{*}{ Characteristics } & \multirow{2}{*}{ Categories } & \multicolumn{2}{|c|}{ Social media affinity } & \multicolumn{2}{|c|}{ Eating attitudes } & \multicolumn{2}{|c|}{ Body dissatisfaction } \\
\hline & & $\mathrm{M} \pm \mathrm{SD}$ & $\operatorname{tor} F(p)$ & $\mathrm{M} \pm \mathrm{SD}$ & t or $F(p)$ & $\mathrm{M} \pm \mathrm{SD}$ & $\mathrm{t}$ or $\mathrm{F}(p)$ \\
\hline Gender & $\begin{array}{l}\text { Male } \\
\text { Female }\end{array}$ & $\begin{array}{l}44.31 \pm 6.71 \\
46.85 \pm 6.04\end{array}$ & $\begin{array}{l}2.22 \\
(.036)\end{array}$ & $\begin{array}{l}36.37 \pm 15.24 \\
38.56 \pm 14.23\end{array}$ & $\begin{array}{l}0.79 \\
(.430)\end{array}$ & $\begin{array}{l}22.37 \pm 9.73 \\
23.09 \pm 9.96\end{array}$ & $\begin{array}{l}0.39 \\
(.698)\end{array}$ \\
\hline Age (year) & $\begin{array}{l}12 \sim 13 \\
14 \sim 15 \\
16 \sim 17\end{array}$ & $\begin{array}{l}45.90 \pm 5.27 \\
45.80 \pm 6.88 \\
44.52 \pm 7.61\end{array}$ & $\begin{array}{l}0.43 \\
(.650)\end{array}$ & $\begin{array}{l}42.10 \pm 13.81^{\mathrm{a}} \\
39.22 \pm 12.94^{\mathrm{b}} \\
27.19 \pm 14.51^{\mathrm{c}}\end{array}$ & $\begin{array}{l}10.46 \\
(<.001) \\
a, b>c^{*}\end{array}$ & $\begin{array}{c}20.29 \pm 8.72^{\mathrm{a}} \\
22.80 \pm 9.92^{\mathrm{b}} \\
26.37 \pm 10.39^{\mathrm{c}}\end{array}$ & $\begin{array}{l}3.30 \\
(.041) \\
c>a^{*}\end{array}$ \\
\hline Grade & $\begin{array}{l}\text { 7th } \\
8 \text { th } \\
9 \text { th } \\
10 \text { th }\end{array}$ & $\begin{array}{l}45.44 \pm 5.80 \\
46.78 \pm 6.12 \\
44.24 \pm 7.08 \\
45.09 \pm 7.22\end{array}$ & $\begin{array}{l}0.67 \\
(.573)\end{array}$ & $\begin{array}{l}42.13 \pm 12.10^{\mathrm{a}} \\
40.59 \pm 15.42^{\mathrm{b}} \\
42.65 \pm 10.25^{\mathrm{c}} \\
27.12 \pm 13.65^{\mathrm{d}}\end{array}$ & $\begin{array}{c}9.37 \\
(<.001) \\
a, b, c>d^{*}\end{array}$ & $\begin{array}{c}20.38 \pm 8.17 \\
21.44 \pm 9.21 \\
20.00 \pm 9.77 \\
27.64 \pm 10.44\end{array}$ & $\begin{array}{l}4.35 \\
(.006)\end{array}$ \\
\hline $\begin{array}{l}\text { Weekly use } \\
\text { (day) }\end{array}$ & $\begin{array}{l}\leq 6(n=23) \\
\text { Every day }(n=91)\end{array}$ & $\begin{array}{l}42.18 \pm 6.69 \\
46.34 \pm 6.21\end{array}$ & $\begin{array}{l}2.68 \\
(.006)\end{array}$ & $\begin{array}{l}36.95 \pm 17.03 \\
37.54 \pm 14.24\end{array}$ & $\begin{array}{l}0.17 \\
(.867)\end{array}$ & $\begin{array}{c}20.91 \pm 8.15 \\
23.15 \pm 10.15\end{array}$ & $\begin{array}{l}0.96 \\
(.337)\end{array}$ \\
\hline
\end{tabular}

*Scheffé test, $p<.050$.

Table 3. Correlations between Social Media Affinity, Eating Attitudes, and Body Dissatisfaction

\begin{tabular}{|c|c|c|c|}
\hline \multirow{2}{*}{ Variables } & Social media affinity & Eating attitudes & Body dissatisfaction \\
\hline & $r(p)$ & $\mathrm{r}(p)$ & $r(p)$ \\
\hline Social media affinity & 1 & & \\
\hline Eating attitudes & $-.37(<.001)$ & 1 & \\
\hline Body dissatisfaction & $-.07(.443)$ & $-.59(<.001)$ & 1 \\
\hline
\end{tabular}

Table 4. Multiple Regression on Eating Attitudes and Body Dissatisfaction

\begin{tabular}{llrrrrrrrrr}
\hline Variables & Categories & $\mathrm{B}$ & $\mathrm{SE}$ & $\mathrm{\beta}$ & $\mathrm{t}$ & $p$ & $\mathrm{R}^{2}$ & Adj. $^{2}$ & $\mathrm{~F}$ & $p$ \\
\hline Eating attitudes & (Constant) & 22.62 & 7.40 & -.47 & 3.06 & .003 & .524 & .511 & 40.29 & $<.001$ \\
& Body dissatisfaction & -0.71 & 0.11 & .33 & 6.77 & $<.001$ & & & \\
& Social media affinity & 0.74 & 0.15 & -.28 & 4.92 & $<.001$ & & & \\
& Grade=10* & -9.14 & 2.25 & & 4.06 & $<.001$ & & & \\
Body dissatisfaction & (Constant) & 27.30 & 5.24 & -.65 & 5.21 & $<.001$ & .368 & .356 & 32.28 & $<.001$ \\
& Eating attitudes & -0.44 & 0.05 & .17 & 7.98 & $<.001$ & & & \\
& Social media affinity & 0.26 & 0.12 & & 2.07 & .041 & & & \\
\hline
\end{tabular}

*Dummy coded (0=7 9th grade, $1=10$ th grade).

was above the moderate level; in other words, adolescents' preferences for SM were higher than usual. This indicated that SM was a major activity and an essential part of these young peoples' daily social lives and interpersonal relationships [6].

An unhealthy diet is a significant health-threatening risk factor, especially for adolescents, who are in a period of rapid physical growth. In this study, $89.5 \%$ of the participants showed a high risk of developing eating disorders. It is well known that negative eating attitudes can lead to dietary disorders. In the study of Chang et al. [24], one-fourth of students responded that they had negative eating attitudes that required professional attention, such as fasting or using diet pro- ducts during the past year. Therefore, education is urgently needed to promote healthy eating attitudes in adolescents.

Body dissatisfaction refers to the degree of how dissatisfied people are with their own bodies [24]. It occurs when people's views about their bodies are negative or when there is a large perceptual difference between their body and the so-called ideal body [25]. In this study, the mean score of the participants corresponded to a mild level of concern with their body shape. The study conducted by Chang et al. [24] of adolescents also showed relatively low levels of body satisfaction. This result is remarkable in adolescents, who are sensitive to external evaluation and are in a period of life when they experience in- 
tense physical changes [12].

This study found significant differences in social media affinity according to gender, as female adolescents shared their interests and preferences more often than male adolescents and used SM as a major means of social interaction. This result aligns with the finding that SM use in Korea was slightly higher among female students (73.7\%) than among male students as (72.6\%) [26]. In addition, the students who used SM every day showed higher social media affinity than those who used SM 6 or fewer days a week. In other words, as SM usage increases, the more likely users are to become dependent daily users who do not miss even one day [9]. Therefore, a practical approach should be used in the education of adolescents, in which they take breaks from SM use and comply with guidelines regarding the appropriate time of SM use, without entirely neglecting their preferences for using SM.

There were significant differences in eating attitude according to participants' age and school grade, and in body dissatisfaction according to age. The study found that younger adolescents had more obsessive eating attitudes and fewer complaints about body appearance. These results suggest the need for younger adolescents to receive proper education related to eating attitudes and for older adolescents to receive education on body dissatisfaction. In this study, no significant difference in eating attitudes was found according to gender. However, Chang et al. [24] reported that female adolescents had a higher prevalence of restrained eating $(30.4 \%)$ than male adolescents $(18.2 \%)$. This issue should be re-examined in further research. Body dissatisfaction among participants in 10th grade was higher than among those in other grades. However, the Scheffé test showed no significant difference. Therefore, this issue also requires re-examination in a further study.

This present study found that social media affinity was related to negative eating attitudes, and that eating attitudes also showed a negative correlation with body dissatisfaction. This finding suggests that exposure to SM, which portrays thinness as the ideal body image, is an important driver of weight loss and the motivation to diet, and that SM directs individuals' perceptions toward body dissatisfaction. In support of other studies, we found that an increased frequency of SM usage due to higher social media affinity was associated with problematic eating attitudes and greater body dissatisfaction [9]. Repeated exposure and thin-ideal internalization through social media affinity has been found to be a strong risk factor for eating pathologies and body dissatisfaction [24]. Other studies have reported that the use of SM and negative eating attitudes that lead to abnormal eating behavior are interrelated, and that SM use is a stronger predictor of dieting behavior than exposure to other traditional media, such as TV and magazines [20]. The associations between spending time using SNS and the severity of SM overreliance is highly relevant to undesirable eating attitudes [9]. Accordingly, the relationship between the time exposed to SM and the influence of SM on abnormal behaviors has been consistently verified [27]. Our study supported these findings.

Studies have found that adolescents who have lower satisfaction with their bodies have higher levels of eating disorders [6]. There is also strong evidence of the influence of SM-mediated body dissatisfaction [24,28]. Facebook, for example, allows users to post photos and provides them opportunities to compare their physical appearance with others, thus placing users at a higher risk of body dissatisfaction, which in turn can increase the risk of subsequent eating disorders [6]. Previous research has shown that body dissatisfaction affects not only the physical health of those with eating disorders, but also their mental health, leading to weight-related depression, anxiety, and low self-esteem [25]. In particular, adolescents who experience depression and stress due to dissatisfaction with their bodies more frequently engage in negative behaviors, including alcohol or drug abuse, smoking, and excessive dieting [29].

This study showed that social media affinity influenced eating attitudes. SM use is reported to have become the most powerful driver of adolescents' eating behaviors [30]. That is, the more exposure adolescents have to seeing idealized thinness on SM, the more likely they are to experience disordered eating attitudes and eating behaviors. Social pressure to pursue slimness leads adolescents to choose unhealthy weightcontrol behaviors and unhealthy eating behaviors [6]. Another similar study showed a significant effect of SM on diet intentions [13].

Our findings suggest that social media affinity plays a major role in body dissatisfaction, supporting previous findings that SM usage is significantly associated with comparisons of appearances [7]. In a study by de Vries et al. [20], the frequency of SM use was positively correlated with frequent comparisons of appearances and more exposure to media messages that conveyed unrealistic body images, lowering people's satisfaction with their body appearance. The idealized body image lauded by the media can be easily recalled from memory and is strongly perceived as a body standard or beauty standard against which everyone's appearance is judged. Regardless of SM type, exposure to the "perfect" body image leads to significantly higher body dissatisfaction [28].

In this study, we applied Festinger's social comparison theory [15], according to which people make self-evaluations by comparing themselves with others. Social media affinity profoundly affected eating attitudes and body dissatisfaction among the adolescents in this study. This suggests that a useful application of this theoretical framework may be helpful 
to plan nursing interventions for SM-using adolescents.

Controlling the use of SM by adolescents would be a monumental and probably futile task. This study suggests that a better approach would be to educate adolescents about SM and its content to minimize the negative impacts of constant exposure to unrealistic body images. In addition, it also suggests the importance of educating SM users to anticipate, understand, and maintain greater control over their personal SM usage. Prevention measures such as media literacy and psychoeducation should place a major emphasis on the relationship of health with eating attitudes and body dissatisfaction. School nurses, as key health educators and healthcare providers for adolescents, have a valuable opportunity to promote adolescents' health. These results can give information on how the school nurse should communicate about SM with adolescents. In addition, families and care providers should be aware of these SM- and health-related issues and discuss them with adolescents.

Social media affinity is expected to increase steadily, and SM will play a principal role in many adolescents' lives. Increased knowledge in this area would lead not only to more realistic views of healthy SM usage, but also help adolescents to use SM constructively to form positive eating attitudes and body images. Therefore, more research is needed to inform intervention efforts.

Our results need to be interpreted in light of the following limitations. First, the sample was restricted to one school in one district in the Philippines. Larger samples that include adolescents from other geographic regions may yield more generalizable results. Second, the cross-sectional nature of this study did not allow us to investigate the long-term effects of social media affinity, such as the development of other psychological problems after prolonged use of SM. Thus, future studies with a longitudinal design will be needed. Third, the data were based on a self-report questionnaire and may be subject to recall bias.

Despite these limitations, the results of this study provide research and practical implications for school nurses, researchers, and SM users.

\section{CONCLUSION}

This investigated the impact of social media affinity on eating attitude and body dissatisfaction in Filipino adolescents. The results confirmed the impact of social media affinity on adolescents' eating attitudes and body dissatisfaction, showing a significant negative relationship between social media affinity and eating attitudes and between eating attitudes and body dissatisfaction. In addition, the multiple regression analysis results indicated that grade, body dissatisfaction, and so- cial media affinity influenced eating attitudes, and that eating attitudes and social media affinity influenced body dissatisfaction in adolescents.

\section{Conflict of interest}

No existing or potential conflict of interest relevant to this article was reported.

\section{REFERENCES}

1. Statista. Number of social media users worldwide from 2010 to 2021 [Internet]. NY: Statista; 2018 May [cited 2019 June 11]. Available from:

https://www.statista.com/statistics/278414/number-of-world wide-social-network-users/

2. We Are Social. Digital 2019: Global internet use accelerates [Internet]. NY: We Are Social; 2019 January 30 [cited 2019 June 11]. Available from:

https://wearesocial.com/blog/2019/01/digital-2019-global-inter net-use-accelerates

3. Lenhart A. Teens, social media and technology overview 2015 [Internet]. Washington, DC: Pew Research Center; 2015 April 9 [cited 2019 june 11]. Available from:

https://www.pewinternet.org/2015/04/09/teens-social-mediatechnology-2015/

4. Pertierra R. Transforming technologies, altered selves: Mobile phone and internet use in the Philippines. Manila: De La Salle University Press; 2006.

5. Caron J, Light J. "Social media has opened a world of 'open communication:"' experiences of adults with cerebral palsy who use augmentative and alternative communication and social media. Augmentative and Alternative Communication. 2016;32(1):25-40. https://doi.org/10.3109/07434618.2015.1052887

6. Saunders JF, Eaton AA. Snaps, selfies, and shares: How three popular social media platforms contribute to the sociocultural model of disordered eating among young women. Cyberpsychology, Behavior, and Social Networking. 2018;21(6):343-354.

https://doi.org/10.1089/cyber.2017.0713

7. Khan GF, Swar B, Lee SK. Social media risks and benefits: A public sector perspective. Social Science Computer Review. 2014;32(5): 606-627. https://doi.org/10.1177/0894439314524701

8. BaeSY, Go EH. A study on the utilization of social media for the vitalization of youth culture. Research Report. Sejong: National Youth Policy Institute; 2015. Report No.: 15-R03.

9. Teo NSY, Collinson SL. Instagram and risk of rumination and eating disorders: An Asian perspective. Psychology of Popular Media Culture. 2019;8(4):491-508. https://doi.org/10.1037/ppm0000205

10. Barry CT, Sidoti CL, Briggs SM, Reiter SR, Lindsey RA. Adolescent social media use and mental health from adolescent and parent 
perspectives. Journal of Adolescence. 2017;61:1-11.

https://doi.org/10.1016/j.adolescence.2017.08.005

11. Kwak S, Woo T, Lee KA, Lee KH. A comparison of dietary habits and influencing factors for vegetable preferences of adolescents in Gyeongnam Province. Korean Journal of Community Nutrition. 2015;20(4):259-272. https://doi.org/10.5720/kjcn.2015.20.4.259

12. Nelson SC, Kling J, Wängqvist M, Frisén A, Syed M. Identity and the body: Trajectories of body esteem from adolescence to emerging adulthood. Developmental Psychology. 2018;54(6):1159-1171. https://doi.org/10.1037/dev0000435

13. Kim Y, Yeo M, Lee M. The effect of media exposure and interpersonal communication on body satisfaction and appearance management behaviors of women in their twenties: Focusing on the role of social norms. Media, Gender and Culture. 2018;33(3):43-84.

14. Javellana GM. Influence of media on body image satisfaction among adolescents. Asia Pacific Journal of Education, Arts and Sciences. 2014;1(1):95-101.

15. Festinger L. A theory of social comparison processes. Human Relations. 1954;7(2):117-140. https://doi.org/10.1177/001872675400700202

16. ABS CBN News. Social media now a player in what, where Filipinos eat: Kantar study. ABS CBN News [Internet]. 2017 Septembr 6 [cited 2019 June 11]. Business. Available from:

https://news.abs-cbn.com/business/09/06/17/social-media-now -a-player-in-what-where-filipinos-eat-kantar-study

17. Kelly B, King L, Jamiyan B, Chimedtseren N, Bold B, Medina VM, et al. Density of outdoor food and beverage advertising around schools in Ulaanbaatar (Mongolia) and Manila (The Philippines) and implications for policy. Critical Public Health. 2015;25(3):280290. https://doi.org/10.1080/09581596.2014.940850

18. Adair LS, Duazo P, Borja JB. How overweight and obesity relate to the development of functional limitations among Filipino women. Geriatrics. 2018;3(4):63. https://doi.org/10.3390/geriatrics3040063

19. Rochelle T, Hu WY. Media influence on drive for thinness, body satisfaction, and eating attitudes among young women in Hong Kong and China. Psychology, Health and Medicine. 2017;22(3):310318. https:// doi.org/10.1080/13548506.2016.1226507

20. de Vries DA, Peter J, de Graaf H, Nikken P. Adolescents' social network site use, peer appearance-related feedback, and body dissatisfaction: Testing a mediation model. Journal of Youth and Adolescence. 2016;45(1):211-224.

https://doi.org/10.1007/s10964-015-0266-4

21. Gerlich RN, Browning L, Westermann L. The Social Media Affinity
Scale: Implications for education. Contemporary Issues in Education Research. 2010;3(11):35-42.

https://doi.org/10.19030/cier.v3i11.245

22. Garner DM, Olmsted MP, Bohr Y, Garfinkel PE. The Eating Attitudes Test: Psychometric features and clinical correlates. Psychological Medicine. 1982;12(4):871-878.

https://doi.org/10.1017/S0033291700049163

23. Evans C, Dolan B. Body Shape Questionnaire:: Derivation of shortened "alternate forms". International Journal of Eating Disorders. 1993;13 (3):315-321.

https://doi.org/10.1002/1098-108X(199304)13:3<315::AID-EAT2 $260130310>3.0 . \mathrm{CO} ; 2-3$

24. Chang FC, Lee CM, Chen PH, Chiu DH, Pan YC, Huang TF. Association of thin-ideal media exposure, body dissatisfaction and disordered eating behaviors among adolescents in Taiwan. Eating Behaviors. 2013;14(3):382-385.

https://doi.org/10.1016/j.eatbeh.2013.05.002

25. Lee J, Yoo J. Influence of body shape perception on self-esteem among normal-weight middle school students in South Korea: The mediating effect of body shape satisfaction and gender differences. Studies on Korean Youth. 2015;26(4):267-297.

https://doi.org/10.14816/sky.2015.26.4.267

26. Ju YW, Lee KN, Choi YJ, Youn EJ. 2017 Survey on the internet usage [Internet]. Naju: Korea Internet and Security Agency; 2018 March [cited 2019 June 11]. Available from:

https://k-erc.eu/wp-content/uploads/2018/07/2017-Survey-onthe-Internet-Usage.pdf

27. Levine MP, Kelly J. Mass media 1: A primer on media literacy's role in the prevention of negative body image and disordered eating. In: McVey G, Levine MP, Piran N, Ferguson HB, Editors. Preventing eating-related and weight-related disorders: Collaborative research, advocacy, and policy change. 1st ed. Waterloo: Wilfrid Laurier University Press; 2012. p. 85-112.

28. Bell BT, Dittmar H. Does media type matter? The role of identification in adolescent girls' media consumption and the impact of different thin-ideal media on body image. Sex Roles. 2011;65:478. https://doi.org/10.1007/s11199-011-9964-x

29. Choate LH. Counseling adolescent girls for body image resilience: Strategies for school counselors. Professional School Counseling. 2007;10(3):317-326.

30. Smolak L, Striegel-Moore RH, Levine MP. The developmental psychopathology of eating disorders: Implications for research, prevention, and treatment. 1st ed. NY: Routledge; 1996. 